\title{
Proceeding
}

Supplementary Issue: Spring Conferences of Sports Science. First International Conference in Iraq on Sport for Peace, 4 April 2019. Baghdad Science Institute, Baghdad, Iraq.

\section{Effect of taking some of dietary supplements according to special forces exercises to develop some physical abilities, speed and accuracy smash shot for badminton young players}

\author{
ABEER DAKHIL HATEM AL-SELMI ${ }^{1}$, FALIH HASHIM FENJAN², SAIF ABBAS JIHAD AL-RUBAYE ${ }^{3}$ \\ ${ }^{1}$ College of Physical Education and Sport Sciences for Women, University of Baghdad, Iraq \\ ${ }^{2}$ College of Physical Education and Sports Sciences, University of Baghdad, Iraq \\ ${ }^{3}$ College of Physical Education and Sport Sciences, University of Misan, Iraq
}

\begin{abstract}
Set dietary program for some of dietary supplements and training for badminton young players, and identifying effect of taking some of the dietary supplementary for badminton young players. The research population :( badminton young players group (Arminian club). For age group (16-18) years the sample is divided in to two experimental groups within each group (6) players, and two for the exploratory experiment which was within the research sample, they were divided in to two groups, the first group take some of the dietary supplements (multivitamin creating) the set exercises by the researchers in the main part of the training unit and the second group (amino acids, vitamins) and the set exercises by the researcher. The scientific approach :( the experimental approach to design the two groups of the pre and posttests). The measurement instruments: physical tests for the explosive power and the power characteristic by speed for the two arms and the legs, besides, the smash shot), after applying the pre-tests, and applying the muscular ability, then applying the exercises for two months set by the researcher. The statistical processing :( the mean was used and the standard deviation and torsion for the one sample, and $(\mathrm{t})$ test for two independent samples).The research results: ( using the exercises and some of the dietary supplements have positive effect on improving some of the physical abilities, speed and accuracy of smash shot skill for badminton young players).The researcher recommends: (depending exercises accompanying with the dietary supplements for badminton young players of age group(16-18) years by the trainers and using dietary

\footnotetext{
Corresponding author. College of Physical Education and Sport Sciences for Women, University of Baghdad, Iraq.

E-mail: abeer@copew.uobaghdad.edu.iq

Supplementary Issue: Spring Conferences of Sports Science. First International Conference in Iraq on Sport for Peace, 4 April 2019. Baghdad Science Institute, Baghdad, Iraq.

JOURNAL OF HUMAN SPORT \& EXERCISE ISSN 1988-5202

(c) Faculty of Education. University of Alicante

doi:10.14198/jhse.2019.14.Proc4.05
}

VOLUME 14 | Proc4 | 2019 | S469 
supplements with training and contests to retain the player's energy. Keywords: Dietary supplements; Special forces; Ability training; Badminton young players.

\section{Cite this article as:}

Al-Selmi, A.D.H., Fenjan, F.H., \& Al-Rubaye, S.A.J. (2019). Effect of taking some of dietary supplements according to special forces exercises to develop some physical abilities, speed and accuracy smash shot for badminton young players. Journal of Human Sport and Exercise, 14(4proc), S469-S476. doi:https://doi.org/10.14198/ihse.2019.14.Proc4.05 


\section{INTRODUCTION AND THE RESEARCH IMPORTANCE}

Sport training is the ideal process make the athletes reach to levels qualifying them to engage in championships and contests via preparing them in various aspects including, the physical characteristics which have prominent and distinguished role to improve other aspects with their integration with each other resulted in making the skill and the activity to reach high level during the contest, most athletes are seeking for what make them able to increase their physical abilities and promote their achievements in the contests, it is obvious amongst to be the best and more effective methods to develop their abilities legally is enhancing organization between good training and using suitable dietary program related to this, we should aware the Dietary supplements role and the manner of giving them, where they are one of the essential aspect as a result of concentration on it and the manner of giving it properly with the training unit, accordingly, proving the players with Dietary supplements suitable with the characteristic to be developed could contribute besides other good training methods set on scientific bases to develop the player's physical and skilful abilities, where the Dietary supplements( amino acids, creatine, vitamins) are the Dietary elements contained the necessary dietary materials, subsequently, it effects positively to promote the physical and skilful abilities for this, could be better to give the Dietary supplements besides the mastering training. from this the importance of the research emerged to know the extent to which taking the Dietary supplements accompanying the muscular training to promote some of the physical abilities, and speed and accuracy of the smash shot for badminton young players (Abdulfatah \& Nasir Aldeen,1993).

\section{The Research Problem}

Badminton includes fast movements and very high ability; the player should have the power but he is in lack of the explosive ability which ensure applying its force with high speed and most of the players suffer from decline of the physical level especially at the last half of the of the second half and this is confirmed by a number of supervisors and specialists. And for the Dietary supplements considered one of the important reasons in the recent years which used to support the players physically, functionally and skilfully, thus the researchers has opined to know effect of some of Dietary supplements accompanying the muscular training ability to promote some of physical abilities and speed and accuracy of crushing hit for badminton young players, hoping that this research scientific development and accuracy of information required to be known related with the players by which we could solve the research problem and to present better level of performance and to promote badminton level with in the celebrations and contributions at the international and local levels.

\section{The Research Objectives}

1. Prepare Dietary program for some of Dietary supplements accompanying the according to special forces exercises training for badminton young players.

2. Identifying effect of some of dietary supplements accompanying the according to special forces exercises to develop some of physical abilities for badminton young players(Khraybit,1996).

3. Identifying effect of some of dietary supplements accompanying the according to special forces exercises to develop some of physical abilities, speed and accuracy smash shot for badminton young players.

\section{The Research Hypotheses}

1. There are differences of statistical significance between the pre and -post training for the research sample in favour of the posttest in some of physical abilities for badminton young players. 
2. There are differences of statistical significance between the pre and -post training for the research sample in favour of the post test to develop some of physical abilities, speed and accuracy smash shot for badminton young players.

3. There are significant differences between the post tests for the research sample in the research variables.

\section{The Research Domains}

Human domain: sample of (Armenian club) young badminton players.

1. Time domain: for the period from (4/1/2018 till 27/2/2018.

2. Spatial domain: indoor court for (Armenian club).

\section{The Research Approach and its Field Procedures}

The research approach: The researcher chose the experimental approach for its suitability with the research problem.

\section{The Research Sample}

The researchers chose the research sample by deliberate method from badminton young players for(Armenian club) of age group whose number(12) players, whereas they are divided randomly with toss in to two experimental and control groups, the first group take some of dietary supplementary( multi creatine , vitamins) and the set exercises by the researcher in the main part of the training unit and the second group( amino acids, vitamins ) and the prepared exercises by the researcher, and the researcher performed the harmony for them and the results has shown the harmony via decline the torsion coefficient from $( \pm 1)$ and this is considered good indicator, and thus the sample is harmonized.

First: Throwing medical ball weight $(2 \mathrm{~kg})($ Saloom,2004).

- The aim of the test: measure the muscular ability for the arm area and shoulder, the explosive power for the arm.

- The devices used: medical ball, measuring tape.

- Description of performance: the examinee stands at the approach area between the two lines, putting the medical ball on one of his hand and another hand based on the ball and the examinee moves towards the approach line of limited distance and when he reaches the line, he pushes the ball from sides pushing the weight provided that not exceeding the approach line.

- Recording: The single examinee has three Sequential attempts, and the wrong performance is considered one attempt, from the three attempts, the best result is counted for the examinee.

Second: vertical jump from stability test (the Sargant) (Abdulhameed \& SubhiHasanein,1980).

\section{The Test Objective}

Measuring the explosive power for the legs.

Tools used in the test: Board fixed on a wall provided that its lower edge high from earth $(150 \mathrm{Cm}$.), to be gradient after that from $(151-400 \mathrm{~cm})$, piece of chalks, the board could be disposed and putting marks directly on the wall according to conditions of the performance.

Third: Test of bending and stretching the arms from front relying during 10 second. (Bastuwisi\& Hasan Hussein,1979) The research objective: measuring the power characterized by speed for the arms. 
- Description of the performance: the player takes front relying, and the distance between the hands as the chest width and when hearing the start signal, the player starts bending and stretching the arms (Abdulhameed \& SubhiHasanein,1980).

- Recoding: the times of bending and stretching are counted for the player during $10 \mathrm{sec}$.

- Every player is given three attempts and the best is counted.

Forth: The test name: the hopping test for max distance in (10 sec.). (Peen,1994).

\section{The Exploratory Experiment}

The researcher performed the exploratory experiment on sample included (2) players from Arminian club, no one was excluded from the main experiment where it as performed on 4/1/2018 at 10:00 a.m. at the indoor hall of the Arminian club.

\section{Pre-Tests}

The researchers performed the pre-tests on 11/1/2018 at 10:00 a.m. at indoor court of the Arminian club, the physical tests and smash shot skill.

\section{The Main Experiment}

First: machinery of taking the dietary supplements used( multi creatine, vitamins and amino acids), the researcher performed dietary program added to the exercises included dietary supplements used( multi creatine, vitamins and amino acids) according to the attached instructions with each supplement, and after asking the specialist in dietary specialty about the method of taking the supplements for (2) months, the group started taking the supplement and the dietary program was applied 4 days in a week by badminton players, knowing that the researcher was supervising taking the dosages by the research sample, and each $\mathrm{s}$ supplement has specified time, where the multi creatine taking time after warm-up(15) minute, the vitamins during the training unit and amino acids after the training unit, provided that the player should take light food(half-filled stomach), where the researcher set two dietary programs as follow:

The first experimental group:

The first group takes two supplements (multi creatine and the vitamins), the researchers used the two supplements together the multi creatine and the vitamins each according to the attached instructions by taking the supplement at taking time as follows as illustrated in table(1).

\section{Experimental group}

The second group take two supplements (amino acids and vitamins) the researcher used the two supplements amino acids and vitamins, where they are used during (2) months and half, provided that be half-filled stomach according to the attached instructions with the dietary supplement as illustrated in table (2).

Principle in loading from 1:3 means increasing stress in the first, second and third week, and decreasing it at the fourth week then increasing it in the fifth, six and seven week and decreasing it in the fourth month, besides using increasing stress principle with decrease the training during two months and half of the application period. 
Table 1. Presentation of dietary system for taking (multi creatine and vitamins) during one week

\begin{tabular}{|l|l|}
\hline Days & Taking manner \\
\hline Friday & $\begin{array}{l}\text { Taking } 17.5 \mathrm{~g} \text {. from creatine supplement in250 g. of water at the beginning of the training } \\
\text { unit and taking one Effervescent tablet of vitamins during the training units. }\end{array}$ \\
\hline Saturday & $\begin{array}{l}\text { Taking } 17.5 \mathrm{~g} \text {. from creatine supplement in250 g. of water at the beginning of the training } \\
\text { unit and taking one Effervescent tablet of vitamins during the training units }\end{array}$ \\
\hline Monday & $\begin{array}{l}\text { Taking } 17.5 \mathrm{~g} \text {. from creatine supplement in } 250 \mathrm{~g} \text {. of water at the beginning of the training } \\
\text { unit and taking one Effervescent tablet of vitamins during the training units }\end{array}$ \\
\hline Wednesday & $\begin{array}{l}\text { Taking } 17.5 \mathrm{~g} \text {. from creatine supplement in250 g. of water at the beginning of the training } \\
\text { unit and taking one Effervescent tablet of vitamins during the training units }\end{array}$ \\
\hline
\end{tabular}

Table 2. Presentation of the dietary supplement for taking amino acids and vitamins during one week

\begin{tabular}{|l|l|}
\hline Days & Taking manner \\
\hline Friday & $\begin{array}{l}\text { One scoop } 3 \mathrm{~g} . \text { in } 300 \mathrm{~mm} \text { of water after the training unit taking one Effervescent tablet of } \\
\text { vitamins during the training units }\end{array}$ \\
\hline ISaturday & $\begin{array}{l}\text { One scoop } 3 \mathrm{~g} \text {. in } 300 \mathrm{~mm} \text { of water after the training unit taking one Effervescent tablet of } \\
\text { vitamins during the training units }\end{array}$ \\
\hline Monday & $\begin{array}{l}\text { One scoop } 3 \mathrm{~g} . \text { in } 300 \mathrm{~mm} \text { of water after the training unit taking one Effervescent tablet of } \\
\text { vitamins during the training units }\end{array}$ \\
\hline Wednesday & $\begin{array}{l}\text { One scoop } 3 \mathrm{~g} \text {. in } 300 \mathrm{~mm} \text { of water after the training unit taking one Effervescent tablet of } \\
\text { vitamins during the training units }\end{array}$ \\
\hline
\end{tabular}

\section{Physical and Skilful Exercises}

The researchers set physical and skilful exercises, and they are applied on Monday (12/1/2018) in the main part of the training unit and total of the units (32) training units, and time of the special training of average (30 minutes) and they are applied on the two experimental groups for 8 weeks of average(4) training units weekly, total of time for the suggested training program(3840) minutes and time of each training unit (120) minutes, where the exercises are applied during the period of special preparing. The researchers used the training stresses by the interval and high stress training for its suitability with requirements of variables currently understudy, besides using the gradation.

\section{Post-Test}

The post tests were performed on research sample in the indoor court of Arminian club on Monday and Wednesday on (10-12-/4/2018) for two days, and the researcher performed to pursue the procedures she depended in the pretests concerned place and time also the used instruments in the tests and those used in measuring also the method of implementing the tests with the help of the assistant team, and to be away from any of variables effect on results and the aim of these tests to identify the development level occurs for the players after taking the suggested dietary supplement( multi creatine and the vitamins) and their applying of suggested exercise and taking the suggested dietary supplements( amino acids and the vitamins) for the second group.

\section{Statistical Means}

PSS was used. 


\section{PRESENTATION, ANALYZING AND DISCUSSION OF THE RESEARCH RESULTS}

Presentation, analysing and discussion of explosive force and the force characterized by speed results for the legs and arms for the first and second experimental groups in the post tests as show in table (3), (4).

Discussing of results: since both the two experimental groups subjected to the same exercises prepared by the researchers also performing the training as one group with the same training units, the differences attributed with the significant differences appeared between the two groups results in the two posttests to the used exercises, where the first group take creatine with vitamins besides the prepared effectiveness used besides the exercises, in spite of occurring improvement for the first group but both according to physiological function as a result of dietary supplement and the actual need of the player during application of skilful performance for smash shot skill, this confirmed by (Abualula and Ahmed Nasir Aldeen) that the force characterized by speed means the muscular system ability to produce fast strength, the matter required degree of harmony to integrate and strong and fast movement at the (Abulula, Ahmed bdulfatah, and Ahmed Nasiraldeen,1933).this to the dietary supplement effectiveness( creatine and the vitamins) by the first experimental group along the period, where the dietary supplement results effects used were effective in tests the explosive force for the arms and legs, whose results are illustrated in the previous table, and this indicated effect of exercises by the researchers, the results showed, the apparent development for this group in explosive force tests. As for the second group taking amino acids with vitamins besides the prepared exercises by the researchers, the results showed apparent development for this group in tests characterized by speed, the researchers attributed the force characterized by force linked with activities required dietary supplement on the first group, and this effect is reflected on obtain good results in this test, the researchers ascribed the development reason to the creatine in its turn recycling (ATP), which provide the body with larger amount of energy and make the muscles to perform the exercise perfectly, in its turn increase the size and the mass of muscles and subsequently, stress exercise and lasts for a long time.( Peen dx;, 1994).

Table 3. Presentation of mean, standard deviation and calculated ( $t$ ) value between two posttests in the physical tests for the first and second groups

\begin{tabular}{|c|c|c|c|c|c|c|c|}
\hline \multirow[t]{2}{*}{ Variables } & \multicolumn{2}{|c|}{ First group } & \multicolumn{2}{|c|}{$\begin{array}{l}\text { Second } \\
\text { group }\end{array}$} & \multirow[t]{2}{*}{$\begin{array}{l}\text { Calculated } t^{\star} \\
\text { value }\end{array}$} & \multirow[t]{2}{*}{$\begin{array}{c}\text { Rate of } \\
\text { error }\end{array}$} & \multirow[t]{2}{*}{$\begin{array}{c}\text { Statistical } \\
\text { significance }\end{array}$} \\
\hline & mean & S.D & Mean & S.D & & & \\
\hline $\begin{array}{l}\text { Test of bend and stretch from } \\
\text { front stand position (10)S. }\end{array}$ & 13,00 & 0,75 & 14,62 & 1,06 & 3,26 & 0,01 & significant \\
\hline Hopping max distance(10) S. & 30,02 & 5,05 & 35,35 & 3,81 & 3,66 & 0,00 & significant \\
\hline $\begin{array}{l}\text { Test of throwing medical ball } \\
\qquad 2 \mathrm{~kg}(\mathrm{~m})\end{array}$ & 14,56 & 1,87 & 12,62 & 0,88 & 2,78 & 0,02 & significant \\
\hline Vertical jump from stability $(\mathrm{cm})$ & 0,74 & 0,33 & 0,44 & 0,11 & 2,43 & 0,04 & significant \\
\hline
\end{tabular}


Table 4. Presentation of mean, standard deviation and calculated ( $\mathrm{t}$ ) value between two posttests in front smash tests for the first and second groups

\begin{tabular}{|l|l|l|l|l|l|l|l|l|}
\hline \multirow{2}{*}{ Variables } & \multirow{2}{*}{$\begin{array}{l}\text { Measuring } \\
\text { unit }\end{array}$} & \multicolumn{2}{|l|}{ First group } & \multicolumn{2}{l|}{ Second group } & $\begin{array}{l}\text { Calculated } \\
\text { t value }\end{array}$ & $\begin{array}{l}\text { Rate of } \\
\text { error }\end{array}$ & Significance \\
\cline { 3 - 9 } & mean & S.D & Mean & S.D & & & \\
\hline $\begin{array}{l}\text { Front } \\
\text { smash } \\
\text { shot }\end{array}$ & Degree & 33,2 & 1,095 & 34,8 & 0,447 & 3,024 & 0,016 & Significance \\
\hline
\end{tabular}

\section{PRESENTATION, ANALYZING AND DISCUSSION OF SMASH SHOT TESTS RESULTS FOR THE FIRST AND SECOND EXPERIMENTAL GROUPS IN THE POST TESTS}

\section{Presentation, analysing and discussion of front smash shot tests results for the first and second experimental groups in the post tests}

The researchers attributed the development for the second experimental group to the dietary supplement.

\section{CONCLUSIONS}

1. The first group taking multicreatine with vitamins besides the setting up exercises by the researchers whose results have demonstrated clear development of this group in explosive power exercises.

2. The second group taking amino acids with vitamins besides the setting up exercises by the researchers whose results have demonstrated clear development of this group in strength characterized by speed tests.

3. The first group taking amino acids with vitamins besides the setting up exercises by the researchers whose results have demonstrated clear development in speed and accuracy of front smash shot in badminton of this group.

\section{REFERENCES}

Abulula Ahmed Abdulfatah, and Ahmed Nasir Aldeen, (1993), Physiology of fitness: (Cairo, DaralfikirAlrarbi house, p85.

Ali Saloom, (2004), Tests and Measurements and statistic in sport field, (AlQadisiyah university) p94.

Bastuwisi Ahmed, and Qasim Hasan Hussein, (1979), Isotonic muscular training in sport activities, 1st edition (Arab homeland press), p715.

Kamal Abdulhameed and Mohammed SubhiHasanein, (1980), Measurement in handball, Cairo, Alfikir Al-arabi house, p133-143.

Peen dx., (1994), C The effect of depth jump and weight tracing on erratic jump research quarterly, sport medicine, p234.

Qasim Hasan Hussein, and Bastwisi Ahmed, (1979), Isotonic muscular training in sport activities, Baghdad, Arab homeland press., p154.

Risan Khraybit, (1996), General Theories in Sport Training (Jordin, Ashoruq house for publishing).

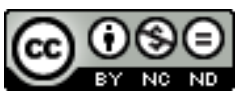

This work is licensed under a Attribution-NonCommercial-NoDerivatives 4.0 International (CC BY-NC-ND 4.0). 